\title{
HIV PREVENTION RESEARCH AMONG SEVERELY MENTALLY ILL LATINAS: AN EXAMINATION OF ETHICAL ISSUES IN THE CONTEXT OF GENDER AND CULTURE
}

\begin{abstract}
We examine the interplay between ethical issues, gender, and culture in the context of our study which examines the context of HIV risk among Puerto Rican and Mexican women with schizophrenia, bipolar disorder, and major depression. Culture and gender are considered in the evaluation of ethical questions related to scientific issues, research team issues, analysis of risks and benefits of participating, confidentiality of data and privacy of the study participants, selection and recruitment, informed consent and decisional capacity, incentives, institutional and peer review matters, data presentation, and community needs. Ethical obligations to research participants and the relevant community are discussed.
\end{abstract}

Key words: latinas, HIV, ethics

\section{LA INVESTIGACIÓN DE LA PREVENCIÓN DE VIH EN MUJERES LATINAS CON ENFERMEDAD MENTAL GRAVE: EVALUACIÓN DE CUESTIONES ÉTICAS EN EL CONTEXTO DEL GÉNERO Y LA CULTURA}

Resumen: El presente estudio examina la interrelación entre los temas éticos, el género y la cultura en el contexto de riesgo a VIH en mujeres de Puerto Rico y México con esquizofrenia, trastorno bipolar y depresión mayor. El género y la cultura se consideran en la evaluación de las cuestiones éticas sobre temas científicos, equipo de investigación, análisis de riesgos y beneficios por participar, confidencialidad y privacidad de datos de los participantes, selección y reclutamiento, consentimiento informado y capacidad de tomar decisiones, incentivos, cuestiones institucionales y de evaluación por pares, presentación de información y necesidades de la comunidad. Se discuten las obligaciones éticas para con los participantes en el estudio y la comunidad relevante.

Palabras clave: latinas, VIH, ética

\section{PESQUISA SOBRE A PREVENÇÃO DO HIV EM MULHERES LATINAS COM ENFERMIDADE MENTAL GRAVE: UM EXAME DE QUESTÕES ÉTICAS NO CONTEXTO DO GÊNERO E DA CULTURA}

Resumo: O presente estudo examina a interrelação, dentre os temas éticos, do gênero e da cultura em um contexto de risco ao HIV, junto a mulheres portadoras de esquizofrenia, transtorno bipolar e depressão profunda, de Porto Rico e México.O gênero e a cultura foram avaliados tendo em vista questões éticas sobre temas científicos como, equipe de pesquisa, análise de riscos e benefícios por participação, confidencialidade e privacidade dos dados dos participantes, seleção e recrutamento, consentimento informado e capacidade de tomada de decisões, incentivos, questões institucionais e de avaliação de pares, apresentação da informação e necessidades da comunidade. Discute-se as obrigações éticas dos participantes do estudo e da comunidade relevante.

Palavras-chave: mulheres latinas, HIV, ética

* Professor and Director, Center for Minority Public Health. Case Western Reserve University, School of Medicine, Department of Epidemiology and Biostatistics, Cleveland, Ohio, United States

Corresponding: Sana.Loue@cwru.edu 


\section{Introduction}

Significant attention has been focused on the ethical issues that arise in the context of research with severely mentally ill persons. Much of this discourse has centered on issues related to capacity and the ability of individuals to give informed consent, the use of incentives, the concomitant possibility that incentives will obviate individuals' ability to refuse participation, and to the use of specific recruitment and retention strategies. However, these issues, and others, have rarely been examined in the context of research with severely mentally ill persons in a specific cultural context or with reference to gender.

In this article, we describe our study which has as one of its principal aims the understanding of the context of HIV risk among Puerto Rican and Mexican women with severe mental illness. We then examine the ethical considerations that arise in the context of specific cultural values. In doing so, we utilize as a foundation the framework developed by Roberts and colleagues for the consideration of ethical aspects of psychiatric research protocols: (1) scientific issues; (2) research team issues; (3) risk- and benefit-related issues; (4) confidentiality; (5) selection, exclusion and recruitment issues; (6) informed consent and decisional capacity issues; (7) incentive issues; (8) institutional and peer/professional review issues; and (9) data presentation issues(1). We add to this framework an additional consideration that we term "community issues."

\section{The study}

\section{HIV Risk among Severely Mentally Ill Persons}

Serious mental illness can affect every dimension of an individual's life, from the performance of the more mundane tasks of living, such as shopping for groceries and using the telephone, to the more challenging aspects of existence. Severely mentally ill individuals may be particularly vulnerable as they attempt to develop and navigate intimate relationships and sexual encounters. Indeed, research has demonstrated that the risk of HIV infection may be heightened for these individuals. A study by Carey et al. found from an examination of aggregated studies that the prevalence of HIV among severely mentally ill persons in the United States is 5\% among females and 10\% among males(2), compared to a prevalence of 0.24 to $0.35 \%$ in the general population(3). Reports indicate that the rate of HIV among severely mentally ill persons ranges from 3\% to $23 \%$, or between 8 and 70 times higher than the U.S. national rate. $(2,4)$ The literature further suggests that among the severely mentally ill, Latinos and women may be at especially high risk $(4,5)$, reflecting the increased risk of HIV among Latinos and women in the general population(6).

This increased risk of HIV infection among severely mentally ill persons has been attributed to various factors. Lower levels of disease severity appear to increase the likelihood of being sexually active. Although greater symptom severity, and sexual dysfunction associated with psychotropic medications may reduce individuals' desire for sexual activity(7), they may be more likely to engage in survival sex due to an inability to manage resources; as a result, they may be increasingly vulnerable to coercion.(8) Individuals' levels of affective instability and behavioral impulsivity are also relevant; a correlation between higher excited symptoms and number of sexual episodes has been noted $(8)$.

Previous studies of HIV risk among severely mentally ill persons have found that many individuals may be at increased risk due to little fear of HIV(9) and a low perception of personal 
risk(10). Cognitive impairments associated with illnesses such as schizophrenia or bipolar disorder may negatively affect an individual's ability to make decisions in their own best interest or appropriately weigh the risks versus benefits of some types of sexual behaviors(11). The prevalence of homelessness among severely mentally ill persons may be as high as $45 \%(12)$, while the prevalence of HIV infection among severely mentally ill homeless persons has been found to be as high as 19\%(13). Sexual relationships in these circumstances are often transient and casual, and may be offered in exchange for shelter and/or food(14).

\section{Study Design}

\section{Sample}

Eligibility for participation in this study required a diagnosis of major depression, bipolar disorder, or schizophrenia; Puerto Rican or Mexican ethnicity if residing in any of six enumerated counties of northeastern Ohio or Mexican ethnicity if residing in San Diego County, California; and age between 18 and 50 years at the time of enrollment. Information about the study was disseminated within the Puerto Rican and Mexican communities through presentations conducted in diverse settings, such as language classes, vocational classes, churches, and support groups. Flyers were also distributed to a broad spectrum of venues, including churches, nightclubs, government assistance offices, social service organizations, laundromats, social clubs, beauty salons, restaurants, grocery stores, and other locales. We also contacted clinicians and counselors serving mentally ill Puerto Rican and Mexican women to apprise them of the study. The presentations and flyers advised individuals that we were conducting a study to better understand how to reduce HIV risk among Puerto Rican and Mexican women who were deprimida (depressed), who had suffered from ataques de nervios (nervous or panic attacks), or who had emotional troubles. We used these terms in order to avoid stigmatizing or embarrassing the individuals who might be interested in participating and who might signify their interest in a public forum. Individuals were provided with the names and telephone numbers of various staff members for additional information about the study.

Individuals who contacted study personnel for more information were advised that the study focused on Puerto Rican and Mexican women who had been diagnosed with major depression, bipolar disorder, or schizophrenia. Interested persons were asked for their consent to a baseline interview to assess eligibility for study participation. The mental health diagnosis was established using the Structured Clinical Interview for Axis I DSM-IV Diagnoses (SCID), described below. Individuals found to have one of the three qualifying diagnoses and who were otherwise eligible to participate were invited to join the study. We then obtained informed consent from the participants for an additional two-part baseline interview, a followup interview each year for two years, and 100 hours of shadowing.

\section{Data Collection}

Interviews were conducted by one of several trained bilingual female interviewers in English and/or Spanish, as indicated by the participant. All interviews were conducted in a manner designed to maximize privacy and confidentiality. Individuals' qualifying diagnosis was made through the administration of the Structured Clinical Interview for Axis I DSM-IV Diagnoses (SCID). The two-part baseline interview following this assessment consisted of questionnaires to assess acculturation level based on language skills and use, migration history, basic demographic information, sexual and drug use histories, and HIV knowledge. Observations during shadowing supplemented the data co- 
llected during these interviews and allowed us to understand the participants' viewpoints regarding key concepts, such as risk, religiosity, spirituality, love, and commitment.

Shadowing required that the interviewer accompany each study participant in the course of her life's activities. To the extent possible, shadowing was conducted in a manner designed to observe similar situations across all study participants. These situations included: interactions with romantic and/or sexual partners, children, and other family members; social situations, such as parties; appointments with psychiatrists, social workers, internists or other physicians; inpatient hospitalization episodes; everyday activities such as church attendance, grocery shopping and interactions with children's school personnel, neighbors, and friends; and interactions in the course of obtaining publicly funded services, such as those that occur at the Social Security office. The study ethnographers also witnessed some participants using drugs and/or approaching men to exchange sex for money or drugs.

All study participants were aware that we were conducting shadowing activities. Whenever possible, shadowing activities were tape recorded or, when this was not possible, were detailed in interviewer notes immediately following the shadowing. The majority of third parties encountered in the course of shadowing activities, such as physicians, family members, and friends, were also aware that the interviewers were conducting shadowing activities and were recording the encounters. However, in order to minimize safety risks to the participants and the interviewers, the true purpose of the interviewers was not revealed to persons selling drugs to the study participants or to those with whom they were engaging in other illegal activities. Study staff were instructed not to participate in any way in observed illegal activities and to leave any situation in which they believed their safety was at risk.

\section{Ethical issues}

\section{Scientific Issues}

It is critical that the design of a study be such that the study yields meaningful, interpretable findings while offering sufficient safeguards to protect the welfare of the study participants(15). Our attention to various ethical issues presented significant challenges methodologically.

First, participation in HIV-related research may itself have effects on HIV risk behaviors (16). At the commencement of participation, each enrolled participant was counseled by a trained interviewer with respect to the mechanisms of HIV transmission and methods to reduce HIV risk. Additionally, each participant was provided with a listing of HIV test sites and was afforded an opportunity at this time to ask questions relating to HIV transmission. It is impossible to know during the course of the study what effect, if any, this time-limited informational session may have had on subsequent participant risk behavior.

Despite the methodological complications that arise from the provision of this information to participants, we believe that it would have been unethical to withhold this basic information. The ethical principle of nonmaleficence requires that the investigative team refrain from doing harm. The withholding of such information would not have impacted participants' ability to obtain such information elsewhere; other avenues for learning about HIV prevention were and are available. However, the withholding of such information would have violated the trust that the participants placed in the investigative team and could have later resulted in a feeling of betrayal. 
The presence of the ethnographer during shadowing may have also had an effect on participant risk behavior. Because of the extended number of hours of shadowing of each participant, we believe that, at least over time, the presence of the ethnographer was unlikely to impact participant behavior. However, it is still possible that her presence may have served to increase or decrease risk behavior. If this is the case, the possible effect is not measurable.

Second, because HIV transmission occurs through social behaviors, any effect of participation on the risk behaviors of our participants may have had implications for their sexual and drug-sharing partners. To the extent that participants report their own behavior change, and to the extent that the team ethnographers witness behavior change, we can assess the impact of participants' behavior change on their partners. However, the effect of study participation itself and the information initially provided to participants on their partners' behavior remains immeasurable.

Finally, a critical issue relates to the observational design of the study and the possibility of an obligation to intervene. If, for instance, an ethnographer observes a participant in a highrisk situation, such as the sharing of injection equipment, or learns of a participant's intent to engage in behavior that would be considered high risk, such as unprotected intercourse with an anonymous sexual partner of unknown HIV serostatus, is there an obligation to intervene? To do so would transform an observational study which seeks to understand in a systematic way the context of elevated HIV risk into a study involving interventions of random form administered at random times to random participants. In short, the findings resulting from such a study would be uninterpretable. In our view, the knowing conduct of a study that would yield findings that are difficult to understand and apply would constitute the exploitation of the research participants and a wasteful use of their time.

\section{Research Team Issues}

Research team issues have been most frequently framed as obligations running from the investigator to the research participants: that participants be treated respectfully, that there is consideration for the welfare of the participants, and that scientific standards be upheld(1). These elements have direct implications for the recruitment and retention of research participants, discussed in detail below. Much less attention has been paid to ethical issues that arise in defining the study team or that flow from the investigator to the members of the study staff.

Community advisory boards, composed of health care providers, representatives from relevant social service organizations, and/or peer representatives of research participants, have often been viewed as liaisons to the participant communities, rather than as integral members of the research team. In contrast, the members of our advisory boards at each site were actively involved in the planning of the study, the design of recruitment and retention strategies, and the interpretation of our findings. Throughout the course of the study, they provided insight into possible solutions to methodological and ethical issues that arose.

This role, however, may provoke various ethical questions. As an example, one mental health provider sitting on one of our advisory boards demanded access to data that had been collected from a study participant who was also a client of the provider's agency. Ethically and legally, the information could not be divulged to the provider without the participant's consent to its release, which the participant did not wish to give. 
The resolution of this dilemma required its examination in the context of the ethical principles of respect for persons, beneficence, and nonmaleficence. The principle of respect for persons includes the obligation to maintain participant privacy and data confidentiality, with relatively few exceptions. In this instance, we did not give the requested data to the health care provider because the participant indicated that it was not to be released. The principle of nonmaleficence required that we communicate our decision to the health care provider in a manner that would not cause harm to the participant, such as might occur if the provider were angered at the participant's refusal to release the data.

In communicating our decision to withhold the data to the provider, we were cognizant not only of these ethical principles, but also of the cultural value of respeto, which refers to the obligation to respect and to pay deference to those in authority. Accordingly, we framed our withholding of the information as an acknowledgement of the legal requirement of confidentiality. In this way, the interests of the participant were not compromised and the requesting party was not embarrassed by our refusal.

Ethical issues related to staff/study team are often framed as issues related to the competence of the team members to conduct the research. Competence and qualifications are often determined based on an assessment of an individual's formal education. However, ethical concerns should prompt a more thorough evaluation of the meaning of "competence" in the context of research that focuses on members of minority communities.

For this study, the project coordinator and all ethnographers were hired from the Latino community. Beyond the implications for re- cruitment and retention of the study participants, discussed below, the ethical principles of beneficence and justice suggest that the benefits of research be made available to the community in which the research is conducted. This precept is reflected in Guideline 10 of the 2002 International Ethical Guidelines for the Conduct of Biomedical Research Involving Human Beings promulgated by the Council of International Organizations for Medical Sciences:

Before undertaking research in a population or community with limited resources, the sponsor and the investigator must make every effort to ensure that:

- the research is responsive to the health needs and the priorities of the population or community in which it is to be carried out; and

- any intervention or product developed, or knowledge generated, will be made reasonably available for the benefit of that population or community(17).

Guideline 20 of the same document, which focuses on strengthening capacity for ethical and scientific review and biomedical research provides that:

Many countries lack the capacity to assess or ensure the scientific quality or ethical acceptability of biomedical research proposed or carried out in their jurisdictions. In externally sponsored collaborative research, sponsors and investigators have an ethical obligation to ensure that biomedical research projects for which they are responsible in such countries contribute effectively to national or local capacity to design and conduct biomedical research, and to provide scientific and ethical review and monitoring of such research.

Capacity-building may include, but is not limited to, the following activities: 
- establishing and strengthening independent and competent ethical review processes/ committees

- strengthening research capacity

- developing technologies appropriate to health-care and biomedical research

- training of research and health-care staff

- educating the community from which research subjects will be drawn(17).

Similar provisions are contained in the CIOMS' 1991 International Guidelines for Ethical Review of Epidemiological Studies(18). It can be argued that the same standard should apply even if the research is not to be conducted in another country, but instead in a marginalized community. By hiring from within the community in which the research is conducted, individuals within that community will have the opportunity to develop the requisite skills for the conduct of research and intervention programs within their own community.

Definitions of "competence" that are premised on the acquisition of formal education and degrees, although seemingly constituting objective criteria, may disproportionately impact members of the minority communities from which the participants come and from which the staff members are to be hired. It is a fallacy to believe that all individuals have equal opportunity and financial ability to obtain a formal education. Indeed, employment as a member of the study team may bring with it tuition benefits and a more flexible work schedule that will permit staff members to obtain a higher education. Accordingly, the selection of staff members should, in our view, focus on the likelihood both that an individual will acquire the skills necessary to continue to work in his or her community and that he or she has the desire to do so, rather than the level of formal education that the individual has achieved.

As indicated previously, the staff members came from the community of the participants and were able to communicate with and understand participants who chose to speak in Spanish. The similarity of staff members to participants, and the staff's familiarity with the community fostered trust between the study team and the participants. However, because the staff and the participants came from the same community, it was not uncommon for them to encounter each other in settings outside of the research context. This may be particularly true because both the staff members and the study participants were women from the same community and, as such, often engaged in the same types of activities at the same venues, such as grocery stores, beauty salons, etc. This could potentially result in a blurring of boundaries and confusion for both the participants and the ethnographers regarding their roles and responsibilities(1921). We addressed this possibility through intensive training of our study team members and by advising participants upon enrollment that the ethnographers were required by the terms of their employment to adhere to specified standards.

The cultural value of respeto may have also been critical to the establishment and maintenance of boundaries in difficult situations. Because the ethnographers were associated with the university, they were seen as deserving of respect; participants often referred to them as "las muchachas de la Universidad" ["the girls from the university"]. One participant commented to one of the ethnographers, " $U d$. es una persona que tiene ética" [You are a person who has ethics"]. The prestige derived from the ethnographers' association with the university did not, however, become a barrier to communication because the boundaries were somewhat 
fluid to accommodate different situations. As an example, some of the participants spoke to the study ethnographers more as peers, because of the similarity in their ages, while other participants assumed a role of "teacher" when the ethnographer was significantly younger than they were.

Continuous training and debriefing of the study team members was critical to the maintenance of boundaries in a culturally appropriate manner. Many times, often as a function of their mental illness, participants would test the ethnographers to see if they would cross the line and engage with them in activities such as drinking, "hanging out," or talking about their own intimate relationships. Training was important to identify strategies of refusal that were culturally sensitive and would not lead to the alienation or embarrassment of the participant.

Questions relating to boundaries often arose in the context of interactions with the male family members of the study participants. Not infrequently, males would make sexually suggestive comments to the ethnographers or invite them on a date. To some extent, this behavior may have been associated with the men's perception of the behavior expected of men. Machismo, for instance, may be interpreted by some men to mean that they must engage in sexual relations with many women, or at least attempt to as evidence of their manhood(22). Again, staff training and role playing were important in identifying strategies to maintain boundaries while not offending the "suitor."

The design of our study raises significant issues related to staff safety. As part of their shadowing responsibilities, ethnographers were required to observe participants engaged in high HIV-risk situations, such as injecting. In addition, some of our study participants came to us with histories of violence against others. These circumstances could be extremely volatile and potentially place the ethnographer in physical danger. Our application of the ethical principle of nonmaleficence also demands that we refrain from creating situations that may place our research participants at increased risk of committing violence against others or suffering violence as a result of our presence. Accordingly, our ethnographers were trained to remove themselves from situations immediately if they and/or the research participant might suffer harm; to shadow in pairs any participant with a history of violence towards others; to refrain from carrying any money during shadowing; and to carry a study-supplied cell phone for emergencies. In addition, ethnographers were instructed to refrain from acknowledging study participants in the presence of third parties unless they were first introduced by the participant or acknowledged by the participant.

\section{Risk- and Benefit-Related Issues}

One of the major benefits attending participation was the potential for participants to form a connection with the ethnographer. Many of our participants, by virtue of their mental illness and, in some cases, co-occurring substance use, were relatively isolated or had become estranged from their families and friends. A large proportion of our participants suffered from episodes of extreme paranoia, so that it was extremely difficult for them to trust others. The majority of our participants' lives were characterized by varying degrees of chaos due to fluctuations in the level of their symptomatology and the relative (in)effectiveness of their medications; economic difficulties attributable to lower levels of education, cognitive difficulties associated with their mental illness, and poor employment prospects; and the instability of persons upon whom they relied for advice, who themselves often suffered from mental illness and/or substance dependence. Partici- 
pation in the study offered the possibility of a stable connection to a stable individual, who could be relied upon to keep their confidences intact.

The development of trust between the ethnographer and the research participant could provide the participant with an opportunity to relate her story, confident that it would not be divulged to others in a way that would be attributable to her. However, many of the encounters with participants were heavily laden with emotion and dealt with highly sensitive topics including the sexual abuse of participants as children and their victimization by romantic or sexual partners. The recounting by participants of these traumatic experiences necessarily prompts the question as to whether our "objective" collection of these experiences as data was necessary and justifiable and whether this "objectification of highly charged emotional events itself [constitutes] a form of violence" $(23, p .2)$ and violates the principle of nonmaleficence, to refrain from doing harm. We informed all of our participants that they could withhold a response to any question and divulge information as they chose. We provided all participants with a listing of resources available in the community that could help them address these traumatic experiences. To our surprise, most participants advised us that the sharing of these experiences was therapeutic for them and, in some cases, represented the first time that they had divulged these experiences to others.

This connection between the ethnographer and the participant could, however, if not handled wisely, be unwittingly and unintentionally transformed into a substantial risk. First, the development of a trusting relationship could inadvertently foster a sense of dependency on the ethnographer. We were particularly concerned that this might occur with participants who were especially isolated from others due to their mental illness. In order to minimize this risk, ethnographers were trained to tactfully remind participants of the nature of the relationship and to refrain from becoming active participants in shadowing situations to the extent possible. As an example, one of our ethnographers was asked to provide interpretation services for a health care provider during a shadowing with the participant in her psychiatrist's office. The ethnographer had been trained to politely refrain from doing so and to indicate that she was not there in the capacity of a service provider, but merely as an observer of the interaction and, as such, could not assume an active role.

We were also concerned that the termination of the relationship between the participants and ethnographers could be traumatic to the participants. In order to reduce this possibility, we marked participants' progress through the study with small reminders of the number of shadowing hours that had been completed and the number of hours that remained until termination of their participation. These "reminders," all bearing the study logo, consisted of key chains, sewing kits, mugs, small canvas tote bags, and t-shirts, distributed respectively at the completion of $10,25,50,75$, and 100 hours of shadowing. (These reminders also served as continuing incentives, discussed in that context below.) At the close of their participation, participants could elect to receive the study's quarterly newsletter and to continue to come to the study's annual reception for participants, community members, study and collaborating university personnel, and advisory board members. We believe that this strategy of small gifts was effective because we were working with women, who appeared to value the gesture. It is uncertain whether male participants in the same kind of study would have responded as well.

Yet another potential risk-or benefit-relates to the effect that participation itself may have on the participant and consequent change in her relations with others. This is best explained by 
example. A number of our participants were initiated into substance use by members of their birth families, including parents, uncles, and/or siblings. Their continuing interaction with these family members centered, to varying degrees, on the mutual use of substances. A change in their substance-using behavior could potentially result in a change in their relations with these family members, who might view the behavior change as a sign of disloyalty to the family, contrary to the value of familismo.

Familismo, which has been referred to as the most important culture-specific value for Puerto Ricans, and possibly other Latino groups as well, has been defined as a cultural value that includes a strong identification and attachment of individuals with their nuclear and extended families, and strong feelings of loyalty, reciprocity, and a solidarity among members of the same family(24). Familismo, consisting of both attitudinal and behavioral components, includes beliefs and attitudes regarding the family with respect to feelings of loyalty, solidarity, and reciprocity and actions associated with those feelings. In some cases, that change may have been welcome, but in others, it could be quite traumatic in view of the specific participants' tenuous emotional bond with anyone. And, in some cases, a refusal to participate in substance use may provoke violence against the participant. As there is no way to predict at the commencement of the study whether and how often this might occur, we attempted to address the possibility by providing participants with referrals to culturally sensitive counseling programs and substance use treatment services. When participants were unable to access these resources due to bureaucratic barriers, we worked with them to ensure access.

\section{Confidentiality}

Ethical issues relating to confidentiality include the safeguarding of data during and after the study, the disclosure to participants of the investigators' obligation to disclose information in certain circumstances, and the management of overlapping relationships between the participants. In addition, the cultural values of familismo and confidencialidad prescribe the nondisclosure of sensitive information about the family to outsiders. Accordingly, participant concerns relating to possible disloyalty to the family also demanded attention. We addressed these concerns by emphasizing the measures that we had implemented to maintain confidentiality and efforts to maintain boundaries between and among participants and those in their social networks.

Because many of these women had had numerous experiences in their lives that suggested to them the impossibility of safely trusting others, it was critical that we protect their privacy and the confidentiality of their data to the maximum extent. We utilized numerous, common strategies such as unique identifiers, locked cabinets and computer passwords, and safeguarded participant lists. It was anticipated that a number of the women and/or third parties in their social and familial circles were using substances and that some exchanged sex for money as a means of survival. Despite the controversy surrounding the validity of certificates of confidentiality(25), we applied for and received a certificate from the National Institute of Mental Health. This certificate protected the data from disclosure through subpoena. In fact, data relating to two participants were demanded by attorneys and we were able to deny access to those data on the basis of the certificate.

We made known to the women through the informed consent process that we would, however, report instances of child abuse. In addition, if we believed that the women would be likely to harm themselves or others, we specifically reserved the right to suggest to them that they present at an emergency room or to their men- 
tal health care provider and, if they refused, to contact the appropriate authority. In fact, in all cases in which we believed the participant would be a danger to herself or others, the participant agreed to accompany us to a hospital emergency department.

Many of the women had interlocking or overlapping relationships with the social and familial networks of other participants. For example, one participant, Berta (not her real name) lived in the same apartment directly across the hall from a second participant, Yvonne (not her real name). Neither one knew that the other individual was enrolled in the study. Each one would talk to the ethnographer about how horrible the other one was. Yvonne made known that she was romantically interested in a man with whom Berta was involved in a sexual relationship. On other occasions, the ethnographer would be in the presence of multiple parties who knew each other but did not know about each other. It was critical that ethnographers be thoroughly trained to guard against inadvertent disclosure of information that was provided by one participant to another or to another individual within their network. Such a disclosure could be seen as a breach of trust by the staff member and a disregard of confidencialidad by the ethnographer and the participant.

\section{Selection, Recruitment, and Exclusion Issues}

The recruitment, selection, and exclusion of participants for this study required that we balance the ethical principles of respect for persons with that of nonmaleficence. Respect for persons demands that we respect each individual's decision to participate, while developing and establishing special protections for vulnerable participants. The principle of nonmaleficence demands that we do not harm. An overemphasis on autonomy could result in the selection of individuals who are too ill to participate without re-experiencing trauma, such as might occur with participants with a co-occurring attachment disorder, while an overemphasis on nonmaleficence would result in the wrongful exclusion of individuals.

We were also concerned that the recruitment process be both nonstigmatizing and noncoercive. Because a diagnosis of mental illness is highly stigmatizing within the Puerto Rican and Mexican communities, and a label of mental illness could result in the ostracism of an individual from her family and friends and bring embarrassment and shame to the family, we refrained from using this term in our recruitment materials. Instead, our recruitment materials sought to recruit women who had been deprimida (depressed), who had suffered from ataques de nervios (nervous or panic attacks), or who had emotional troubles. Additional details regarding the focus of the study were provided individually to women who approached us about participation.

\section{Informed Consent and Decisional Capacity Issues}

Our informed consent process provided information relating to all elements specified in the governing federal regulations, including the fact that this was research, the purpose of the research, the procedures involved, the risks and benefits, alternatives to participation, the duration of participation, and who could be contacted for additional information and in case of emergency.

We developed an informed consent process for not only the severely mentally ill women who would be participating, but for their family and health care providers who would be interviewed, with participants' permission, during the course of the study. In some circumstances, however, it was not advisable to reveal the ethnographer's function, the reason 
for her presence, or how the ethnographer and participant had become acquainted, or to seek consent from unknown third parties who might be present at the time. This was the case, for example, when the ethnographer accompanied a participant to church, to a large family gathering, or observed the participant in a nightclub. Disclosure of the ethnographer's purpose could have compromised the safety of the participant and/or the ethnographer and/or resulted in the participant's ostracism once her mental illness became known to others. This situation is not uncommon in the context of qualitative research. As recommended by other researchers, when asked directly about our presence, we allowed the participant to respond whenever possible and, when that was not possible, disclosed our status as researchers(26).

All informed consent documents were written at the sixth grade reading level and were made available in English and in Spanish. In translating the informed consent documents into Spanish, we found that some words commonly used in the Mexican community had entirely different meanings in the context of Puerto Rican culture. As an example, in discussing the \$20 incentive, our Puerto Rican participants understood 20 pesos to mean $\$ 20$, but our participants of Mexican ethnicity understood pesos to refer to cents and 20 pesos equaled 20 cents; for these participants, $\$ 20$ was 20 dolares. Efforts to identify appropriate language for both the Mexican and Puerto Rican participants were further complicated by the insistence of the institutional review board that we utilize words in the Spanish translation that were at a significantly higher reading level than that achieved by the majority of our participants and that an institutionally-developed clause be included at the end of each form to advise participants of their rights, which was also written at a reading level substantially beyond that of our participants. These complexities, which seemed to obstruct rather than to facilitate the informed consent process(27), were particularly troublesome to participants suffering from paranoia, who could not understand what was written and who were unsure whether they should trust the research team.

The initial assessment of capacity was made by the project coordinator, trained by one of the study team psychiatrists to conduct this assessment. We assessed decision-making capacity based on whether the prospective participant (1) could communicate a choice, (2) was able to understand the relevant information and explain it to us in her own words, (3) could explain to us the impact of participation on her daily life, and (4) could explain to us the risks and benefits to her of participating in the study(28).

Although federal regulations do not identify severely mentally ill persons as a class in need of special protections in research, it is clear that, as a result of impaired cognitive ability, at least some individuals may be considered vulnerable. Vulnerable research participants are those who "have insufficient power, prowess, intelligence, resources, strength or other needed attributes to protect their own interests through negotiations for informed consent"'(29, p.72). Accordingly, we developed a multi-step procedure to further assess capacity in instances in which it may have been questionable. We did not, however, utilize this procedure with all participants because to do so would have compromised the autonomy of many of the participants by giving them protection that they did not require. Indeed, its application to all participants could have inadvertently resulted in their further stigmatization and infantilization(30).

\section{Incentive Issues}

Disagreement exists regarding the ethicality of offering an incentive to research participants, with some scholars decrying its use and others 
viewing it as appropriate in at least some circumstances(31-34). Concern has been voiced, in particular, that an incentive could be coercive, that is, threaten the individual with physical, psychological, or social harm in order to compel her to do something, or that the incentive could serve as an undue inducement by being so attractive that potential participants might ignore potential risks associated with participation or be unable to exercise proper judgment as a result $(1,35,36)$. In setting the level of an incentive, it is critical that a balance be achieved so that the rate of payment is sufficiently high to avoid the exploitation of the participants and sufficiently low to avoid the possibility of coercion or undue inducement(37).

Our participants received an incentive of $\$ 20$ at each of the following time points: the completion of part 2 and again part 3 of the baseline interview, completion of the first follow-up interview at the end of the first year, and completion of the second follow-up interview at the end of the second year. The amount was set in consultation with members of our advisory boards. Our advisory board members believed that this amount was sufficient both to recognize the time contribution of the research participants and to express our gratitude for their efforts(38), without being coercive or constituting an undue inducement to individuals who were of limited economic means. The feedback that we have received from participants suggests that the consistent interaction with our ethnographers and the referrals to supportive services served as the primary motivation for participation in the study, rather than this monetary incentive.

\section{Institutional and Peer/Professional Review Issues}

Federal regulations require that institutions receiving federal funding for research have in place an institutional review board, charged with the responsibility of reviewing research protocols in order to safeguard the research participants(39). International guidelines recommend not only review by an institutional review board, but also consultation with a community advisory board $(17,18)$. Neither the regulations nor the international guidelines, however, offer suggestions for the resolution of conflict between the two boards.

Unfortunately, we experienced conflict between our institutional review board and our community advisory boards in San Diego and Cleveland on various issues. The two advisory boards appeared to work from a consensus model in their attempts to resolve disagreement, as would sometimes occur, for instance, with respect to the translation of various words or processes for recruitment and retention of study participants. Unfortunately, the institutional review board appeared intransigent, despite contrary recommendations from the advisory committees. As an example, our informed consent documents had been written at a sixth grade reading level in both English and Spanish; the Spanish words chosen could be understood by both Puerto Rican and Mexican participants. Our institutional review board insisted that we use Spanish words that were at a reading level considerably above that of many of our participants, and the words that were mandated were not understandable by both our Puerto Rican and Mexican participants. The IRB wished us to eliminate from our listing of study benefits several elements of the study that were specifically identified by both CABs as representing benefits to participation, despite extensive explanations as to why these were culturally considered to be benefits.

These actions by the IRB were often viewed by our CAB members as paternalistic and condescending and were interpreted as messages that the community members were simply too ignorant to understand what was in their own best interest. These community responses to 
the demands of the IRB were reminiscent of charges leveled by investigators of developing countries in response to ethical commentaries suggesting that placebo-controlled trials are per se unethical, regardless of existing local conditions and despite the decisions of local $\operatorname{IRBs}(40)$. Indeed, the decisions of the IRB inadvertently rendered recruitment and retention more difficult. This was not a result of the requirements of participation, but resulted from the complexity of the IRB-mandated language and the consequent levels of frustration experienced by paranoid, prospective participants.

\section{Data Presentation Issues}

We viewed our $\mathrm{CAB}$ members as equal partners and regularly consulted them regarding their interpretations of our aggregated qualitative findings. This allowed us to better understand the perspective of our research participants. We took great care to provide the members with detail that was sufficient for them to offer their insights, but not so detailed that they might identify one or more participants based on the situations described. This was of particular concern to us in view of the limited number of agencies and organizations that provide services to the communities with which we were working and the consequent possibility that a service provider sitting as a member of our CAB might be able to identify a particular individual based on a scenario.

\section{Community Issues}

Data gathered during the course of our study from participants, their family members, and providers revealed a pattern of inadequate access to care for their mental illness. This lack of access appeared to result from numerous systemic barriers, including a relative dearth of trained, Spanish-speaking mental health providers; a lack of familiarity with and inability to navigate the social service bureaucracies that were encountered; alienation from friends and family due to the mental illness; and, for some participants, a fear of law enforcement officials. Whether, and the extent to which, researchers should be engaged in advocacy efforts on behalf of the communities with which they work remains a disputed issue. However, the principle of justice, as reflected in CIOMS' International Guidelines for Ethical Review of Epidemiological Studies(18), would seem to suggest that it is incumbent upon researchers to assume an advocacy role in at least some circumstances:

Honesty and impartiality are essential in designing and conducting studies, and presenting and interpreting findings. Data will not be withheld, misrepresented or manipulated. Investigators may discover health hazards that demand correction, and become advocates of means to protect and restore health. In this event, their advocacy must be seen to rely on objective, scientific data.

That advocacy role could assume one or more of a variety of forms. Accordingly, we are in the process of working with our CABs to identify appropriate funding sources and to develop new protocols that would provide services to these communities, as well as continue with research efforts.

\section{Conclusion}

Culture and gender are important factors to be considered in conjunction with an evaluation of ethical issues that arise in the context of research. These factors should be considered when evaluating ethical questions related to scientific issues, research team issues, an analysis of the risks and benefits of participation, confidentiality of the data and privacy of the study participants, selection and recruitment, informed consent and decisional capacity, incentives, institutional and peer review matters, 
data presentation, and community needs. Many studies would benefit from the formation of community advisory boards to assist in this process.

\section{Acknowledgements}

This research was supported in part by the National Institute of Mental Health (R01 63016).

\section{References}

1. Roberts LW, Geppert CMA, Brody JL. A framework for considering the ethical aspects of psychiatric research protocols. Comprehensive Psychiatry 2004; 42(5): 351-363.

2. Carey MP, Weinhardt LS, Carey KB. Prevalence of infection with HIV among the seriously mentally ill: Review of the research and implications for practice. Professional Psychology: Research and Practice 1995; 26: 262-268.

3. Rosenberg PS. Scope of the AIDS epidemic in the United States. Science 1995; 270: 1372-1375.

4. Cournos F, McKinnon K. HIV seroprevalence among people with severe mental illness in the United States: A critical review. Clinical Psychology Review 1997; 17: 259-269.

5. Otto-Salaj LL, Heckman JG, Stevenson LY, Kelly JA. Patterns, predictors and gender differences in HIV risk among severely mentally ill men and women. Community Mental Health Journal 1998; 34 : 175-190.

6. Centers for Disease Control. HIV/AIDS among Hispanics in the United States. Atlanta, Georgia: Centers for Disease Control, 2004.

7. Fuller M, Sajatovic M. Drug Information Handbook for Psychiatry. $5^{\text {th }}$ ed. Cleveland, Ohio: LexiComp., Inc., 2005.

8. McKinnon K, Cournos F, Herman R. HIV among people with chronic mental illness. The Psychiatric Quarterly 2002; 73: 17-31.

9. Sacks MH, Perry S, Graver R, Shindledecker R, Hall S. Self-reported HIV-related risk behaviors in acute psychiatric inpatients. Hospital \& Community Psychiatry 1990; 41: 1253-1255.

10. Carey MP, Carey KB, Kalichman SC. Risk for human immunodeficiency virus (HIV) infection among persons with severe mental illnesses. Clinical Psychology Review 1997; 17: 271-291.

11. Young DA, Zakzanis KK, Bailey C, Davila R, Griese J, Sartory TA. Further parameters of insight and neuropsychological deficit in schizophrenia and other chronic mental disease. Journal of Nervous and Mental Disease 1998; 186(1): 44-50.

12. Kalichman SC, Kelly JA, Johnson JR, Bulto M. Factors associated with risk for HIV infection among chronic mentally ill adults. American Journal of Psychiatry 1994; 151(2), 221-227.

13. Susser E, Valencia E, Conover S. Prevalence of HIV infection among psychiatric patients in a New York City men's shelter. American Journal of Public Health 1993; 83: 568-570.

14. Kalichman SC, Carey MP, Carey KB. Human immunodeficiency virus (HIV) risk among the seriously mentally ill. Clinical Psychology: Science and Practice 1996; 3: 130-143.

15. Roberts LW. Ethical dimensions of psychiatric research. A constructive, criterion-based approach to 
HIV prevention research among severely mentally ill latinas - S. Loue

protocol preparation: The Research Protocol Ethics Assessment Tool (RePEAT). Biological Psychiatry 1999; 46: 1106-1119.

16. Des Jarlais DC, Gaist PA, Friedman SR. Ethical issues in research on preventing HIV infection among injecting drug users. Science and Engineering Ethics 1995; 1: 133-144.

17. Council of Organizations for Medical Sciences, International Ethical Guidelines for the Conduct of Biomedical Research Involving Human Beings. Geneva, Switzerland: CIOMS, 2002.

18. Council of Organizations for Medical Sciences, International Guidelines for Ethical Review of Epidemiological Studies. Geneva, Switzerland: CIOMS, 1991.

19. Boman J, Jevene R. Ethical evaluation in qualitative research. Qualitative Health Research 2000; 10: 547-554.

20. Orb A, Eisenhauer L, Wynaden D. Ethics in qualitative research. Journal of Nursing Scholarship 2001; 33: 93-96.

21. Seal DW, BloomFR, Somlai AM. Dilemmas in conducting qualitative sex research in applied field settings. Health Education and Behavior 2000; 27: 10-23.

22. Mosher DL. Macho men, machismo, and sexuality. Annual Review of Sex Research 1991; 2: 199-247.

23. Harvey P, Gow P. Introduction. In P. Harvey, P. Gow (eds.), Sex and Violence: Issues in Representation and Experience (pp. 1-17). London: Routledge, 1994.

24. Triandis HC, Marin G, Betancourt H, Lisansky J, Chang B. Dimensions of familism among Hispanic and mainstream Navy recruits, 1982. Cited in G. Marin, Influence of acculturation on familism and self-identification among Hispanics. In Ethnic Identity: Formation and Transmission among Hispanics and Other Minorities (G. Knight, M. Bernal eds.).

25. Haggerty LA, Hawkins J. Informed consent and the limits of confidentiality. Western Journal of Nursing Research 2000; 22(4): 508-514.

26. Ensign J. Ethical issues in qualitative research with homeless youth. Journal of Advanced Nursing 2003; 43(1): 43-50.

27. Roth LH, Lidz CW, Meisel A, Soloff PH, Kaufman K, Spiker DG, Foster FG. Competency to decide about treatment or research: An overview of some empirical data. International Journal of Law and Psychiatry 1982; 5: 29-50.

28. Appelbaum PS, Grisso T. Assessing patients' capacities to consent to treatment. New England Journal of Medicine 1988; 319: 1635-1638.

29. Levine RJ. Ethics and Regulation of Clinical Research. New Haven: Yale University Press, 1988.

30. Stanley B, Stanley M, Lautin A, Kane J, Schwartz N. Preliminary findings on psychiatric patients as research participants: A population at risk American Journal of Psychiatry 1981; 138(5): 669-671.

31. McNeill P. Paying people to participate in research: Why not? Bioethics 1997; 11: 390-396.

32. Dunn L, Gordon N. Improving informed consent and enhancing recruitment for research by understanding economic behavior. Journal of the American Medical Association 2005; 293: 609-612. 
33. Lemmens T, Elliott C. Justice for the professional guinea pig. Amerian Journal of Bioethics 2001; 1: 51-53.

34. Wilkinson M, Moore A. Inducements revisited. Bioethics 1999; 13: 114-130.

35. Faden R, Beauchamp TL. History and Theory of Informed Consent. New York: Oxford University Press, 1986.

36. Office for Protection from Research Risks. IRB Guidebook, 1993. Available at http://www.hhs.gov/ ohrp/irb/irb_guidebook.htm

37. Beauchamp TL, Jennings B, Kinney ED, Levine RJ. Pharmaceutical research involving the homeless. Journal of Medicine and Philosophy 2002; 27(5): 547-564.

38. Grady C. Payment of clinical research subjects. Journal of Clinical Investigation 2005; 115(7): 16811687.

39. 45 Code of Federal Regulations 46.101 (2006).

40. Hyder AA, Dawson L. Defining standard of care in the developing world: the intersection of international research ethics and health systems analysis. Developing World Bioethics 2005; 5(2): 142-152.

Recibido el 14 de mayo de 2006.

Aceptado el 22 de agosto de 2006. 